\title{
Effect of bleaching teeth with hydrogen peroxide on the morphology, hydrophilicity, mechanical and tribological properties of enamel
}

\section{F.T. Rodrigues ${ }^{1}$, A.P. Serro ${ }^{1,2^{*}}$, M. Polido ${ }^{2}$, A. Ramalho ${ }^{3}$, C.G. Figueiredo- Pina $^{4,5}$}

${ }^{1}$ Centro de Química Estrutural, Instituto Superior Técnico, ULisboa, 1049-001 Lisboa, Portugal

${ }^{2}$ Centro de investigação Interdisciplinar Egas Moniz, Instituto Superior de Ciências da Saúde Egas Moniz, Quinta da Granja, 2829-511 Caparica, Portugal

${ }^{3}$ Department of Mechanical Engineering, University of Coimbra, R. Luis Reis Santos, 3030-788 Coimbra

${ }^{4}$ Department of Mechanical Engineering, Setúbal School of Technology, Instituto Politécnico de Setúbal, 2910-761 Setúbal, Portugal

${ }^{5}$ Center of Physics and Engineering of Advanced Materials, Instituto Superior Técnico, ULisboa, 1049-001 Lisboa, Portugal

*Corresponding author: anapaula.serro@ist.utl.pt 


\section{Abstract}

The process of tooth whitening is intended to restore the original color of teeth. It consists of the application of oxidizing agents, including hydrogen peroxide. Although these products considerably improve the color of teeth, their effects on other properties of enamel are not fully understood. The purpose of this work was to study the effects of hydrogen peroxide concentration on hydrophilicity, roughness, morphology, mechanical and tribological properties of human tooth enamel. Human teeth were subjected to bleaching sessions containing 6, 15 and $35 \%$ hydrogen peroxide in order to achieve a similar level of whitening. The enamel roughness and morphology were characterized by atomic force microscopy (AFM) and scanning electron microscopy (SEM). Vickers microindentation hardness data were obtained. The hydrophilicity was determined using the captive bubble method. Reciprocating, ball-on-flat friction and wear tests were conducted in artificial saliva using zirconia as the ball and polished enamel as the flat specimens. Although all three test solutions improved tooth color, they also changed the properties of the enamel. Morphological and roughness changes were observed, and there was a decrease in hardness and wear resistance. The wettability was nearly unaffected. It was found that the $15 \%$ hydrogen peroxide solution damaged the enamel the least. It was concluded that there is an ideal concentration of hydrogen peroxide for whitening treatments.

Keywords: Bleaching/whitening teeth; hydrogen peroxide; enamel; wear; wettability; mechanical properties. 


\section{Introduction}

Teeth whitening or bleaching is a treatment commonly used in dentistry and consists in restore the natural color of teeth or even get a whither color [1]. The darkening of the teeth occurs due to extrinsic and/or intrinsic factors. The former appear as a result of accumulation of chromophore substances, for example from food, drinks or tobacco, associated to poor oral hygiene, which leads to the formation of an organic film that covers the external surface of the teeth. In contrast, the intrinsic factors are related with changes in the teeth structure/composition, especially of dentin. Intrinsic stains may appear associated to aging, antibiotics, overuse of fluoride, and are most difficult to remove [2].

The enamel is the hardest tissue of human body, being highly mineralized ( $97 \%$ in weight) and essentially constituted by non-stoichiometric hydroxyapatite (Hap). Moreover, it also contains about $1 \%$ of organic material, primarily proteins such as amelogenin and enamelin, and $2 \%$ of water [3]. The enamel microstructure consists in nanosized inorganic HAp prisms or rods with different orientations, covered by a thin layer of enamelin and encapsulated by proteins (primarily hydrophilic ameloblastin) [4]. Enamel hardness is related with the mineral and protein content [4,5]. The latter is responsible by some ductility and consequent toughness [5]. Because the quantity of these compounds varies with depth, the enamel hardness also varies depending on the location in the teeth [4].

The dental bleaches are oxidizing agents, based generally in hydrogen peroxide $\left(\mathrm{H}_{2} \mathrm{O}_{2}\right)$ with concentrations between 3 to $40 \%$, which penetrate the dental enamel eliminating the coloring substances. The bleaching teeth mechanism is not totally understood, but some authors believe that the hydroxyl radical $\left({ }^{\circ} \mathrm{OH}\right)$ cleaves the double bonds present in chromophores, making these molecules reflect less light, which produces a whitening effect $[1,6]$. It has been reported that the use of light sources during the bleaching process improves the efficiency of whitening [7].There are three main mechanisms usually proposed in the literature to explain the teeth bleaching by the combined action of UV radiation and peroxide [8]. UV cleavages the $\mathrm{C}-\mathrm{O}, \mathrm{H}-$ $\mathrm{O}$ and $\mathrm{HO}-\mathrm{OH}$ bonds of chromophore molecules due to high radiation energy ( $\approx 3.5 \mathrm{eV}$ for the used wavelength). The absorption of photons by peroxide leads to the formation of free radicals that will cleavage the chromophore molecules. In addition, the absorption of photons increases the reactivity of the chromophore molecules to the peroxide, due to the increase of the energy of its $\mathrm{C}=\mathrm{O}$ bonds, $\mathrm{C}=\mathrm{C}$ and $\mathrm{C}=\mathrm{C}-\mathrm{C}=\mathrm{C}[9]$.

The effect of bleaching teeth on the enamel properties is a controversial subject. Although several studies do not evidence significant modifications in the enamel properties [10-12], others showed that bleaches lead to changes in the enamel surface and also enamel bulk properties [13,14]. Most of the changes reported are probably due to low $\mathrm{pH}$ and oxidative effect of bleaching products that decrease the quantity of hydroxyapatite and proteins [15]. These changes lead to a decrease in microhardness [16,17], alterations in surface morphology $[14,16]$ and lower wear resistance [13]. Morphological changes in enamel can also affect optical properties and bacterial adhesion [18]. 
The aim of the present study is to investigate, in a global way, the effect of hydrogen peroxide used in dental whitening treatments, on human enamel properties. Three concentrations (6, 15 and 35\%) were tested. Besides whiteness level, also the morphology, hydrophilicity, mechanical and tribological behavior of enamel were evaluated. As far as the authors know, until date no one did a so complete evaluation of the effect of this whitening agent in a single work.

\section{Materials and Methods}

\subsection{Teeth preparation and initial color measurement}

Five healthy human molars were extracted and stored in a thymol solution $(0.1 \%)$ at $4^{\circ} \mathrm{C}$ in order to ensure aseptic conditions. The molars were cut longitudinally and then the lateral (facial and lingual) external surfaces were grinded and polished with SiC sandpapers and clothes to 1 $\mu \mathrm{m}$ diamond paste, in order to obtain a polished flat enamel surface. The polished samples were then half cut in order to obtain 4 samples/tooth.

All the samples were then stained during 48 hours in $10 \mathrm{~mL}$ of black tea solution (2 $\mathrm{g}$ in 50 $\mathrm{mL}$ ) at room temperature [19]. After that, the samples were rinsed and storage in distilled and Milli-Q deionized (DD) water at $4^{\circ} \mathrm{C}$.

The color of all stained samples was determined by using a color spectrophotometer (SpectroShade ${ }^{\mathrm{TM}}$ Micro). Two measurements were done in each polished flat surface $(n=40)$.

\subsection{Bleaching and color control}

Hydrogen peroxide (35\% from JMGS Lda) was used to prepare solutions with different concentrations $(6,15$ and $35 \% \mathrm{v} / \mathrm{v})$. The stained samples were submitted to bleaching treatments comprising 4-11 consecutive bleaching sessions, depending on the peroxide concentration, to obtain a maximum whiteness (shade B1, according to Vita Classical scale). The color of the stained samples was measured before bleaching and after each bleaching session (each specimen was its own control), using the spectrophotometer referred above ( $\mathrm{n}=$ 10 per condition). Each bleaching session (protocol adapted from [20] consisted in the immersion of the dental samples in $10 \mathrm{~mL}$ of $\mathrm{H}_{2} \mathrm{O}_{2}$ solution during 10 minutes. In order to activate the peroxide, the immersed samples were irradiated during $30 \mathrm{~s}$ with ultraviolet radiation $(\lambda=350 \mathrm{~nm}$ ), every 2.5 minutes (total time of irradiation $4 \times 30 \mathrm{~s}$, see Figure 1).

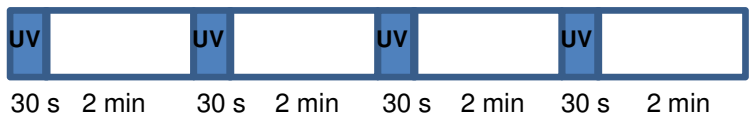

Figure 1. Scheme of the steps in the bleaching treatment session in $\mathrm{H}_{2} \mathrm{O}_{2}$. 
The differences in color were calculated using the following equation [21]:

$$
\Delta E=\sqrt{\Delta \mathrm{L}^{2}+\Delta a^{2}+\Delta b^{2}} \quad E q \cdot 1
$$

where $\Delta E$ is the Euclidean distance between 2 points in the 3-dimensional space of shade and corresponds to the color difference, the coordinate $L$ represents the shade alterations in the black and white scale, $a$ represents shade and saturation in the red-green axis, and $b$ represents saturation in the blue-yellow axis [21]. $\Delta L, \Delta a$ and $\Delta b$ represent the difference between the coordinates L, $a$, and $b$, respectively, at the beginning and at the end of the bleaching session.

After bleaching the samples were kept in Milli-Q deionized (DD) water at $4^{\circ} \mathrm{C}$.

\subsection{Surface morphology}

Samples surface morphology was studied using an atomic force microscope (AFM) (Nanosurf Easyscan2). The roughness (Ra) of the polished flat surfaces was determined from images $\left(100 \times 100 \mu \mathrm{m}^{2}\right)$ obtained with silicon tips (PPP-NCLAuD-10) and a load of $20 \mathrm{nN}$. Images were analysed using the software WSxM 5.0 Develop 4.0.

Furthermore, the untreated, treated and worn surfaces were characterized by scanning electron microscopy observation (SEM) (Hitachi S2400 equipment). The samples were previously coated with a gold-palladium thin layer.

\subsection{Microhardness}

The Vickers hardness of the samples polished flat surface was measured using a microhardness tester (Struers Duramin), with an applied load of $1.96 \mathrm{~N}$ and a dull time of $30 \mathrm{~s}$ before and after bleaching treatment. Fifteen measurements were performed per condition.

\subsection{Wettability}

The hydrophilicity of the samples (before and after staining, and after bleaching treatment) was evaluated through the measurement of the water contact angle, using the captive bubble method, since this method allows keeping the tooth always immersed in water. In contrast, the sessile drop method, commonly used by several authors [22], implies the drying of the samples, which shall lead to structural changes [23]. Air bubbles $(3-4 \mu \mathrm{L})$ were generated with a microsyringe with an end curved needle underneath the polished flat surfaces of the teeth, immersed in DD water. Images were acquired at set time intervals during $30 \mathrm{~s}$ using a video camera (JAI CV-A50) mounted on an optical microscope (Wild M3Z) and connected to a frame grabber (Data Translation DT3155). 
The acquisition and analysis of the images were performed using the ADSA-P software (Axisymmetric Drop Shape Analysis Profile). At least eight bubbles were done per condition.

\subsection{Tribological tests}

Reciprocating ball-on-plate tests were performed using polished flat dental samples as plates and $3 \mathrm{~mm}$ diameter zirconia spheres (Technoball). The tests were carried out at room temperature in a nanotribometer (CSM Instruments), in lubricated conditions using artificial saliva $(\mathrm{pH}=7.15)$ with the composition given in Table 1.

Table 1. Artificial saliva composition.

\begin{tabular}{cc}
\hline Reagent (g/L) & Concentration (g/L) \\
\hline $\mathrm{NaCl}$ & 0.600 \\
$\mathrm{KCl}$ & 0.720 \\
$\mathrm{CaCl}_{2}$ & 0.166 \\
$\mathrm{KH}_{2} \mathrm{PO}_{4}$ & 0.680 \\
$\mathrm{Na}_{2} \mathrm{HPO}_{4}$ & 0.337 \\
$\mathrm{KSCN}$ & 0.060 \\
$\mathrm{NaHCO}_{3}$ & 1.500 \\
\hline
\end{tabular}

The wear tests were performed at a frequency of $2 \mathrm{~Hz}$, during $10 \mathrm{~min}$, at a maximum linear speed of $0.65 \mathrm{~cm} / \mathrm{s}$. A normal load of $20 \mathrm{mN}$ was applied, which corresponds to an initial contact stress of $158 \mathrm{MPa}$ (calculated using the Hertz equation for elastic contact). This value is within the range of 35 to $350 \mathrm{MPa}$, determined assuming an occlusal contact area of $2 \mathrm{~mm}^{2}$ and the values reported in the literature for the normal masticatory load (70 to $700 \mathrm{~N}$ ) $[24,25]$. A stroke length of $1 \mathrm{~mm}$ was used since, in vivo, the occlusal contact is between 0.9 and $1.2 \mathrm{~mm}$. For each group of samples, ten wear tests were performed. During the wear test, the friction coefficient was monitorized.

A Mitutoyo Surftest SJ-500 was used to obtain three 2 D profiles for each wear track, along the $1 \mathrm{~mm}$ of the length. The profiles were aligned considering the original surface out of the wear track as the reference plane. Numerical integration was used to obtain the area of the transverse wear profile, as shown on the Figure 2. Finally, the removed wear volume was obtained integrating the three wear profiles along the track length. 


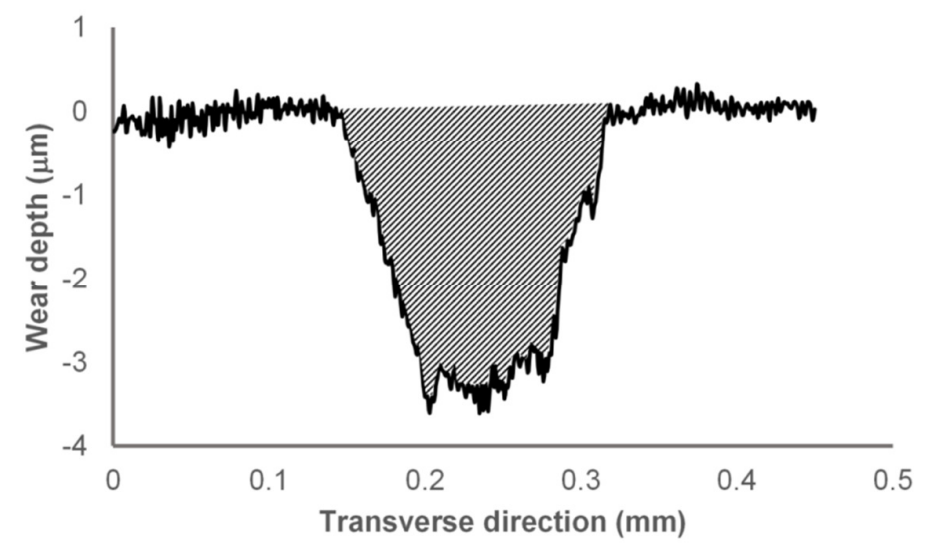

Figure 2. Example of numerical integration of 2D profile of a wear track.

The surface roughness of the wear tracks was estimated form AFM images and the wear mechanisms were investigated using SEM.

\subsection{Statistic analyses}

Statistical analyses were performed using R Project software v. 3.2.0 $0^{1}$. Measures are presented as mean \pm standard deviation, unless otherwise specified. ANOVA test was used to determine if the different group means are significantly different. Tukey's test was done for multiple comparisons. The significance level chosen was 0.05 .

\section{Results and discussion}

The objective of this research work was to evaluate the effect of the peroxide treatment on the tribological behavior of the enamel. The enamel samples were submitted to whitening treatments in solutions with different peroxide concentrations until all of them have similar whitening level, in order to understand the effect of exposition time versus harmful potential of the solution on the enamel properties. It was verified that the increase of the peroxide concentration leads to a decrease of the solution $\mathrm{pH}$. The acidic medium shall demineralize dental hard tissues [26]. In addition, it increases the amount of free radicals that may attack the organic part of the enamel [4]. The chosen peroxide solutions concentrations for this work were $6 \%, 15 \%$ and $35 \%$. The lowest is usually used for whitening process at home, while $35 \%$ is used at office. The later concentration is very hostile for oral mucosal tissues and special protection is needed [27].

Teeth wear may result in inefficient contact of the teeth during mastication and may lead to bad function and deterioration of the temporomandibular joint. In order to understand the

\footnotetext{
${ }^{1} \mathrm{R}$ Project is a free software environment for statistical computing and graphics. It is available in $\underline{\mathrm{https}}$ ://www.rproject.org/
} 
possible structural changes of the teeth induced by whitening, the treated and untreated samples were characterized in terms of hydrophilicity, hardness and surface morphology.

During all experimental work, careful was taken to maintain the teeth samples hydrated in order to preserve de original structure of enamel.

The enamel tribological behavior was evaluated using zirconia $\left(\mathrm{ZrO}_{2}\right)$ spheres as counterbody. This material, which is usually used in the manufacture of artificial crowns, has a much higher hardness (1200 HV) than that of enamel and thus, will allow testing the wear behavior of enamel in harsh conditions. The tests were performed in lubricated medium using artificial saliva to mimetize the oral conditions.

\subsection{Effect of the bleaching agent concentration on enamel color}

The exposition time of the samples to the peroxide solution required to obtain the same level of whiteness decreases with the increase of the solution concentration. The evolution of the color difference, $\Delta E$, during the bleaching treatment (measurement after each session) is given in Figure 3. In fact, the number of sessions needed to achieve shade B1 from Vita Classical scale, which corresponds to maximum whitening, decreases with the increase of the percentage of hydrogen peroxide in the solution. The number of sessions ranges between 4 to $35 \%$ concentration and 11 to concentration of $6 \%$ (Figure 3a), which corresponds respectively to $40 \mathrm{~min}$ and $110 \mathrm{~min}$. The same trend was reported in other studies [28,29].

The total time of treatment which is needed to achieve a certain level of whiteness may be represented by a power function of the hydrogen peroxide concentration (Figure 3b). Sulieman, et al. observed a similar behaviour [10]. According to Kwon et al. the mechanism that leads to changes in tooth color involves the diffusion of the radicals from peroxide into the tooth structure and their interaction with chromophore molecules [8]. Since free radicals have low molecular weight, they can easily penetrate through the enamel inter-prismatic spaces following the Fick's second law. Since the efficiency of the treatment varies with the peroxide concentration through a power function of negative exponent, the reduction in exposition time with the increase of the bleaching agent concentration is higher for lower concentrations.
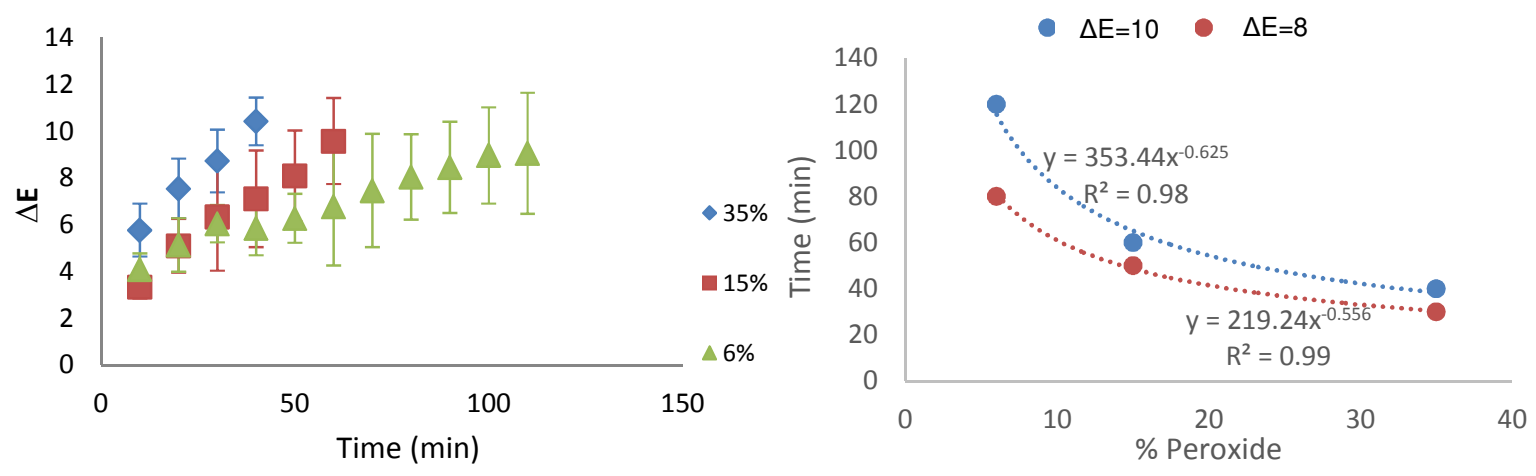
Figure 3. a) Evolution of color difference $(\Delta E)$ in function of bleaching exposition time for different concentrations of $\mathrm{H}_{2} \mathrm{O}_{2}(6,15$ and $35 \%)$. Each point corresponds to one bleaching treatment session. Error bars correspond to standard deviation. b) Relationship between total treatment time and hydrogen peroxide concentration (\%) to achieve two different levels of whitening: $\Delta E=8$ and $\Delta E=10$.

\subsection{Effect of the bleaching agent concentration on enamel morphology}

After bleaching, the roughness of all surfaces increased. Table 2 presents the average values estimated from AFM images analysis. The initial average surface roughness of the teeth was $36 \mathrm{~nm}$. After treatment, it increased to values between $58 \mathrm{~nm}$ and $162 \mathrm{~nm}$. A similar trend was reported by other authors for solutions of $6 \%$ [16], 15\% [30], and $35 \%$ [14] of peroxide. The observed increase in roughness is clinically significant to improve biofilm retention. In fact, it was verified that the adhesion of Streptococcus sanguinis was higher on enamel surfaces with $\mathrm{Ra}=148.6 \mathrm{~nm}$ than in surfaces with $\mathrm{Ra}=36.7 \mathrm{~nm}[18]$.

Table 2. Microhardness, roughness outside and inside of the wear tracks, before and after the treatments with different hydrogen peroxide concentrations.

\begin{tabular}{lccc}
\hline $\begin{array}{l}\text { Tooth } \\
\text { treatment }\end{array}$ & $\begin{array}{c}\text { Ra outside } \\
\text { wear tracks } \\
(\mathrm{nm})\end{array}$ & $\begin{array}{c}\text { Ra inside wear } \\
\text { tracks }(\mathrm{nm})\end{array}$ & $\begin{array}{c}\text { Microhardness } \\
\left(\mathrm{Kg} / \mathrm{mm}^{2}\right)\end{array}$ \\
\hline $\begin{array}{l}\text { Without } \\
\text { treatment }\end{array}$ & $36 \pm 23$ & $39 \pm 21$ & $359 \pm 19$ \\
$6 \% \mathrm{H}_{2} \mathrm{O}_{2}$ & $107 \pm 21$ & $139 \pm 20$ & $225 \pm 20$ \\
$15 \% \mathrm{H}_{2} \mathrm{O}_{2}$ & $58 \pm 17$ & $94 \pm 25$ & $235 \pm 15$ \\
$35 \% \mathrm{H}_{2} \mathrm{O}_{2}$ & $162 \pm 15$ & $131 \pm 21$ & $207 \pm 20$ \\
\hline
\end{tabular}

Whitening leads to morphological changes on the enamel surface. SEM images of untreated sample and samples treated with $6 \%$ are very similar (Figure $4 a$ and $4 b$ ). However, with increasing peroxide concentration features associated with the chemical attack of the peroxide to enamel start to appear, from pitting for the solution with $15 \%$ (Figure 4c) and delamination for solution with $35 \%$ (Figure 4d). These erosion features are analogous to the ones reported by Miranda et al. [14]. 
Morphological changes may be associated to enamel demineralization, due to the low $\mathrm{pH}$ of the bleaching solutions. It is known that enamel, when exposed to solutions with $\mathrm{pH}<5.5$ begins to dissolve [31]. This shall occur in all the studied situations, since the $\mathrm{pH}$ of three peroxide solutions used in this work are below this value $(\mathrm{pH}=1.16$ for $35 \% ; \mathrm{pH}=2.48$ for $15 \%$ and $\mathrm{pH}=3.49$ for $6 \%$ ). This phenomenon occurs because $\mathrm{H}^{+}$ions from the acidic medium react with $\mathrm{OH}^{-}$ions in solution to form $\mathrm{H}_{2} \mathrm{O}$ [32]. With the decrease of $\mathrm{OH}^{-}$concentration, the equilibrium of the hydroxyapatite dissociation reaction (Eq. 2) is displaced to the right, so more $\mathrm{Ca}^{2+}$ and $\mathrm{PO}_{4}{ }^{3-}$ will be formed to achieve a new state of equilibrium.

$$
\mathrm{Ca}_{10}\left(\mathrm{PO}_{4}\right)_{6}(\mathrm{OH})_{2}(\mathrm{~s}) \longleftrightarrow 10 \mathrm{Ca}^{2+}{ }_{(\mathrm{aq})}+6 \mathrm{PO}_{4}{ }^{3-}{ }_{(\mathrm{aq})}+2 \mathrm{OH}_{(\mathrm{aq})}^{-} \quad \mathrm{Eq} .2
$$

Generally, delamination is associated to fatigue wear or internal pressure built up, resulting from expansion of gases. In the present case, the delamination observed for $35 \%$ (Figure $4 \mathrm{~d}$ ) was probably due to the retention of gas in the enamel structure during treatment, e.g. $\mathrm{CO}_{2}$ resultant from the cleavage reaction of chromophore molecules.
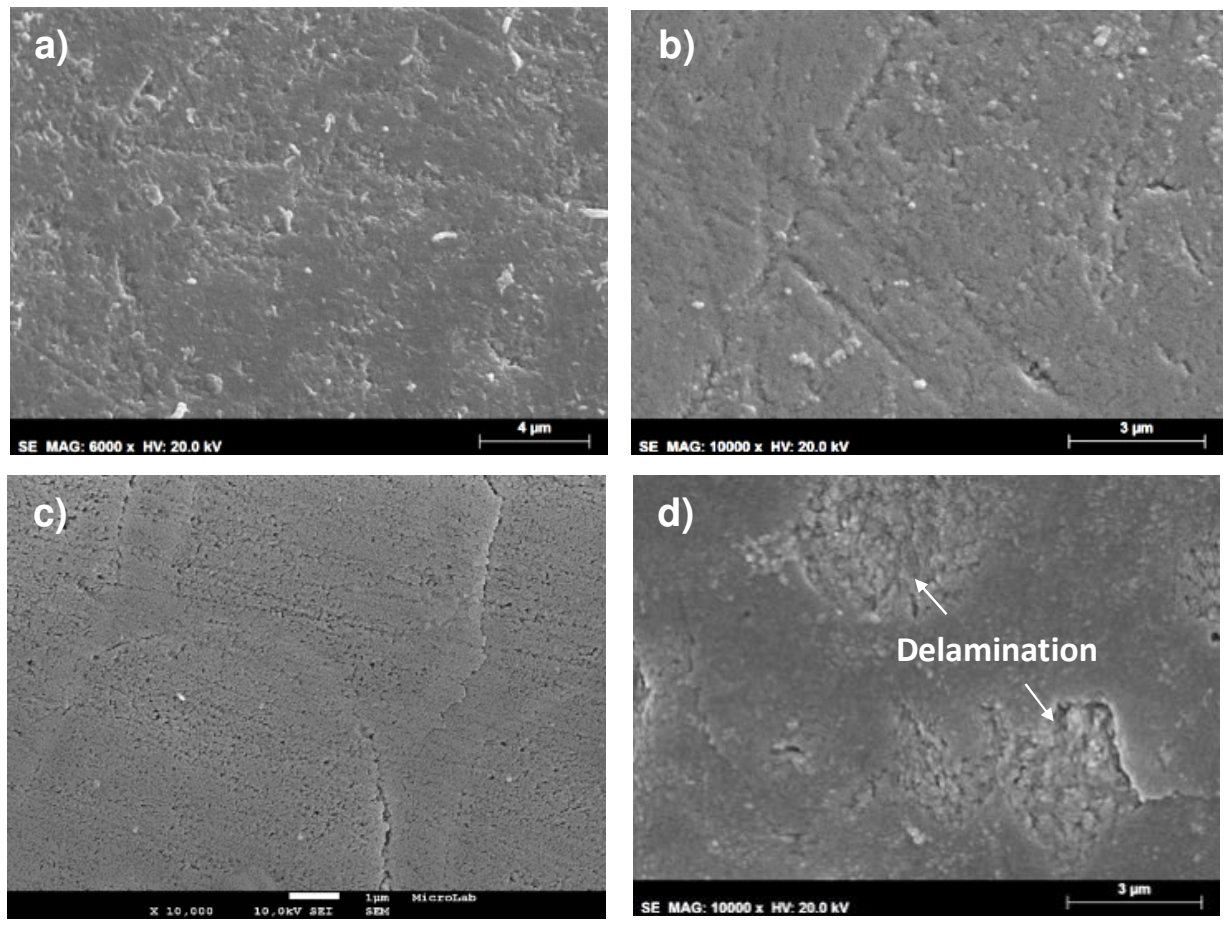

Figure 4. SEM images of enamel surface a) before and after treatment with b) $6 \%$ c) $15 \%$ and d) $35 \%$ of hydrogen peroxide. (Scale markers in the figures correspond to $4 \mu \mathrm{m}, 3 \mu \mathrm{m}, 1 \mu \mathrm{m}$ and $3 \mu \mathrm{m}$, respectively) 


\subsection{Effect of the bleaching agent concentration on enamel mechanical properties}

The results show that the bleaching treatment leads to dramatic decreases of the enamel hardness (Table 2). Enamel microhardness is directly related to the mineral content and structure of enamel, its degree of heterogeneity, the preparation of the tooth and the type of tooth [13,33]. Before treatment the microhardness of enamel was $359 \pm 19 \mathrm{HV}$. This value is within the range of values found in the literature [34]. After treatment, a significant decrease of hardness occurs for all concentrations ( $p$-value $<0.001$ ). Among the treated samples, only the concentrations $15 \%$ and $35 \%$ led to values statistically different ( $p$-value $=0.0034$ ). The impact of the bleaching treatment on hardness is controversial. Some studies show a decrease of hardness after treatment $[16,35,36]$, while other studies did not reveal any impact $[37,38]$. This discrepancy may be related with the exposure time to the bleaching agent, $\mathrm{pH}$ of the solutions and treatment procedure.

Since the applied load is relatively high $(1.96 \mathrm{~N})$, it is possible to detected structural changes in deeper regions. The observed reduction in micro hardness, induced by the treatments with the different concentrations of peroxide, shows that demineralization must have occurred not only at the surface, but also in depth. The loss of mechanical resistance after treatment shall be due to the combined effect of demineralization and degradation of the organic matrix of the tooth $[2,14]$.

\subsection{Effect of the bleaching agent concentration on enamel hydrophilicity}

The knowledge of the water contact angle is important because it can influence the absorption of water, the adhesion of biomolecules and bacteria, and the tribological behavior/surface lubrication. Figure 5 presents the results of the wettability study of the enamel samples.

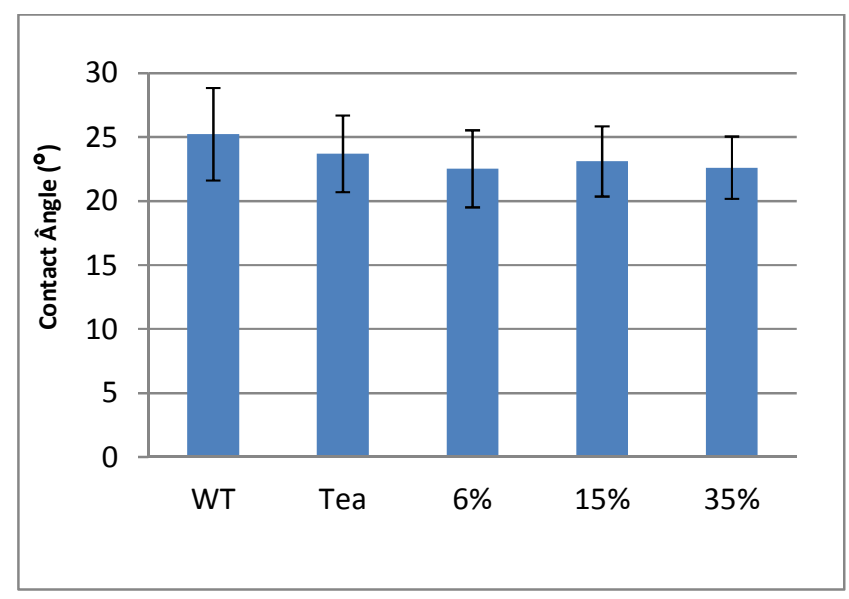


Figure 5. Water contact angles of the enamel samples without any treatment (WT), after stained with tea and after bleaching treatment at different $\mathrm{H}_{2} \mathrm{O}_{2}$ concentrations. Error bars correspond to standard deviation.

The contact angle values obtained before treatment are lower than the reported by other authors $\left(55.3^{\circ}\right.$ to $\left.80^{\circ}\right)$ [22]. This difference may be related to the surface preparation and method of measurement used (sessile drop for the referred authors vs captive bubble in the present work). The dental exposition to tea and the bleaching treatment leads to a slight decrease in the water contact angle ( $p$-value $<0.0132)$. However, the contact angles obtained after exposition to tea and after bleaching treatment were not statistically different between them.

\subsection{Effect of the bleaching agent concentration on enamel tribological properties}

The bleaching treatment deteriorates the enamel structure, resulting in a dramatic increase of wear. However this increase is not directly proportional to the peroxide concentration. Figure 6 shows that, after treatment, the wear coefficient increases approximately 47 fold when the $15 \%$ peroxide solution is used and more than 80 fold to $6 \%$ and $35 \%$. For untreated samples the wear coefficient is of the order of $1 \times 10^{-4} \mathrm{~mm}^{3} / \mathrm{Nm}$, while for treated samples the wear coefficients are all higher than $5 \times 10^{-3} \mathrm{~mm}^{3} / \mathrm{Nm}$. Mundra et al. also reported an increase in enamel wear of bovine teeth after bleaching treatment [39]. The increase on wear coefficient is consistent with the decrease of the treated samples hardness and increase of the samples roughness (Table 2), reflecting the enamel structural deterioration due to the treatment. Concerning these parameters, the most significant differences between the treated samples are related to the roughness. In a rougher enamel surface, the hydroxyapatite crystals are more easily bent in the asperity contact with the counterbody, leading to higher wear. It should be noted that in a previous work it was found that enamel wear is very sensitive to the counterface roughness [40].

The friction coefficient is affected by the whitening treatment (Figure 6). The friction coefficient before treatment was 0.24 and after exposure to peroxide, it increased to values comprised between 0.67 to $15 \%$ and 1.18 to $35 \%$. The increase in the average friction coefficient after this type of treatment was previously reported in the literature [39]. This increase follows the increase in the average roughness after treatment (see Table 2), and shall be due to the increase of mechanical interlocking between the asperities of the sliding contacting surfaces. The high friction values obtained for samples treated with $35 \%$ also point for adhesion. 


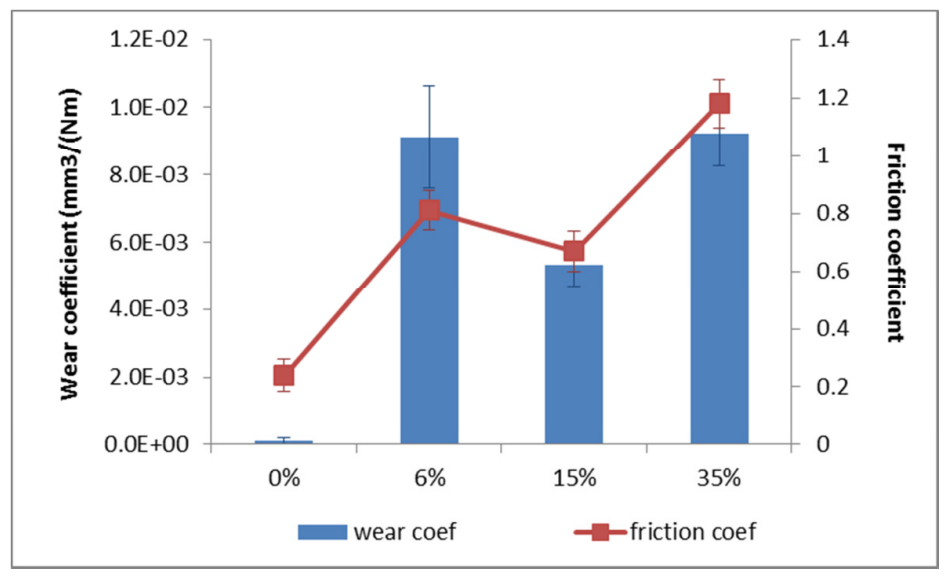

Figure 6. Wear coefficient and friction coefficient for untreated samples and treated with different concentrations of peroxide. Error bars correspond to standard deviation.

The analysis of SEM and AFM images of the wear tracks in the untreated samples (Figure $7 \mathrm{a}$ and Figure $8 \mathrm{a}$, respectively) revealed a very polished wear track. Usually polishing wear is due to the combined effect of mechanical action and chemical reaction. In the present work, the wear tests were carried out in artificial saliva which, due to its saline composition, may interfere with teeth mineralization. This process opposes to the teeth material loss induced by wear. However, more studies would be needed to understand the role of mineralization during wear. On the treated samples, the wear tracks are significantly larger and rougher (SEM images (7b to d) and AFM images ( $8 b$ to d)). AFM analysis shows that for concentrations of 6 and $15 \%$, the roughness inside the wear tracks was higher than outside (Table 2). The opposite was found for $35 \%$, because in these samples delamination occurred both inside and outside the wear tracks (Figures $4 \mathrm{~d}$ and $8 \mathrm{~d}$ ). For all treated samples, a scale-like removal was observed, as a result of detachment of lamellar particles. Usually this is associated to subsurface fatigue phenomena. This mechanism origins higher wear rates, as it was shown in Figure 6. Teeth wear by surface delamination have been observed in several works [40-42]. For samples treated with 6 and $35 \%$, features associated to abrasion wear were not identified, even though the high difference in hardness between enamel samples and the counterbody (zirconia). Same scratches were observed for untreated sample and sample treated with 15\% (Fig 8a) and c)).

For samples treated with $6 \%$ peroxide, it was observed an abrupt increase in the friction coefficient at about 150 seconds (Figure 9b), probably due to the change of dominant wear mechanisms (from polishing wear to fatigue wear). This shows a change of wear regime from mild wear (untreated samples) to severe wear (treated samples). Due to technical issues, it was not possible to analyse the zirconia ball to infer about the eventual transference of material to the counterbody. However, the high friction coefficient obtained for $35 \%$ solution suggests adhesion at least for this condition. 

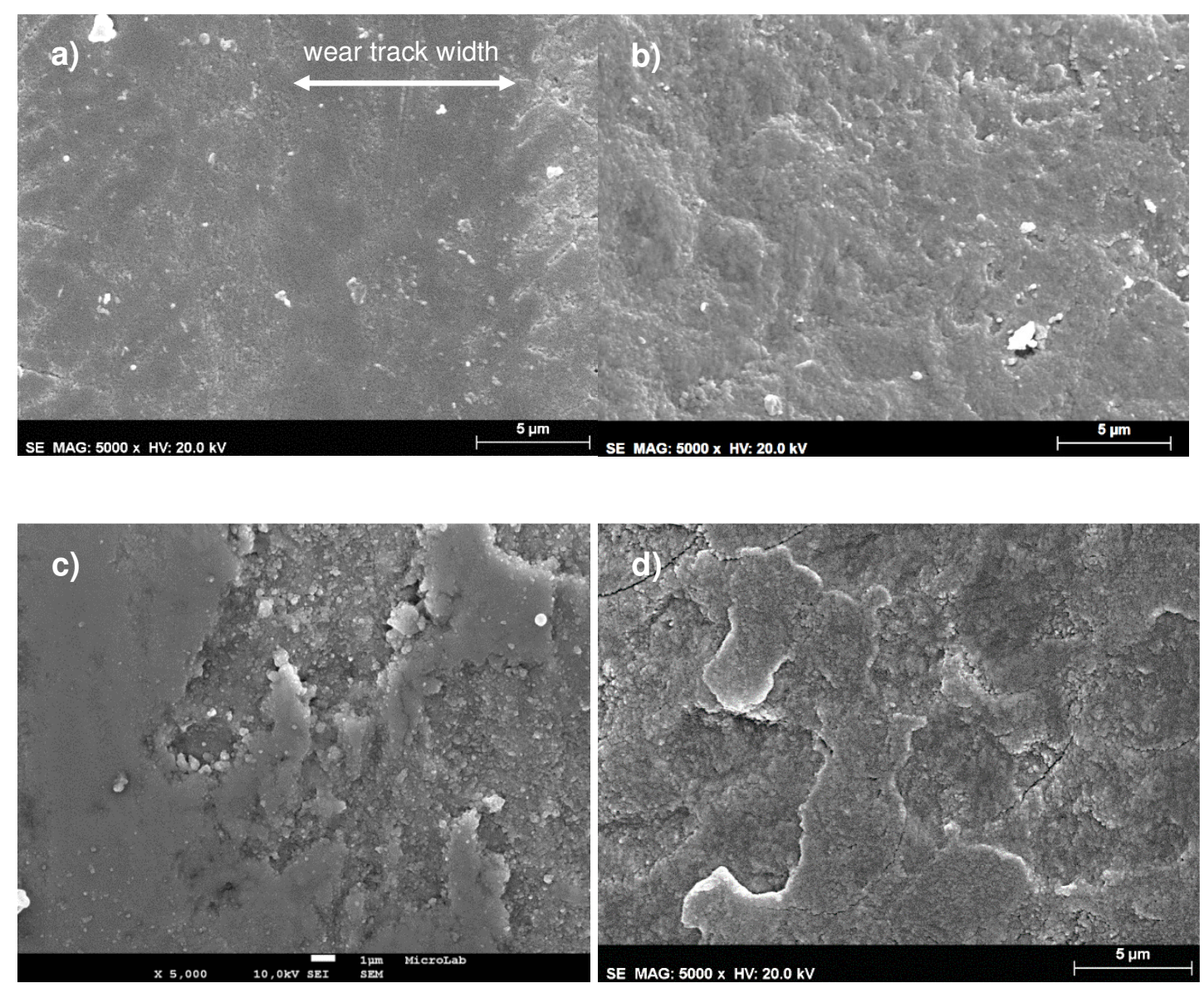

Figure 7. SEM Images a) before treatment and after treatment with different concentrations of peroxide b) $6 \%$, c) $15 \%$ and d) $35 \%$. For the treated samples, images were obtained inside the wear tracks. (Scale markers in the figures correspond to $5 \mu \mathrm{m}, 5 \mu \mathrm{m}, 1 \mu \mathrm{m}$ and $5 \mu \mathrm{m}$, respectively)

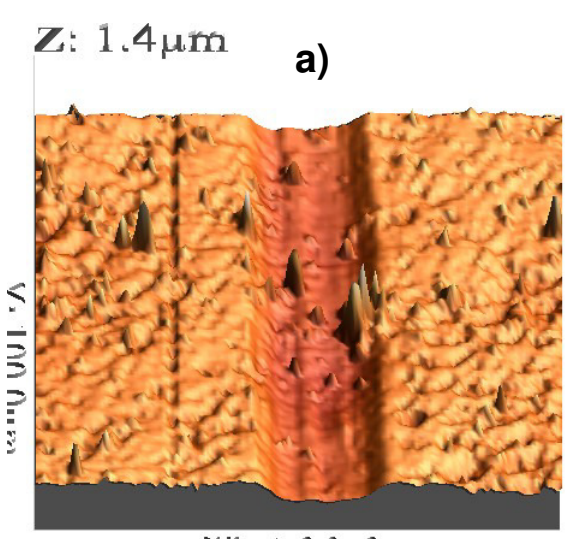

X:- $-00.0-10$

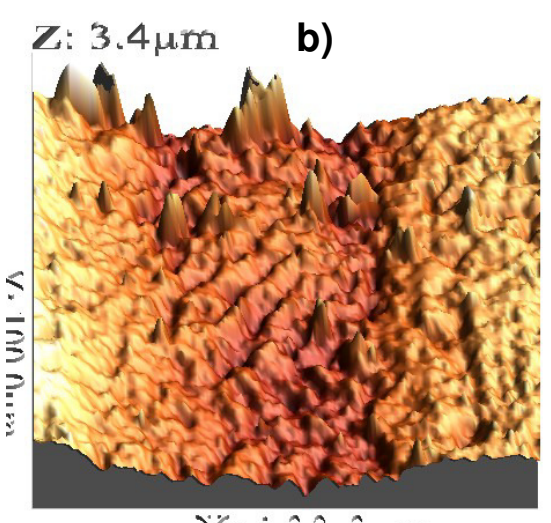

$x:-00.0, \cdots$ 


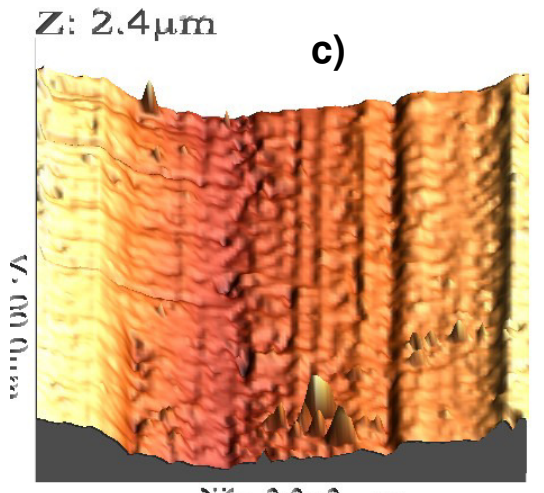

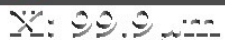

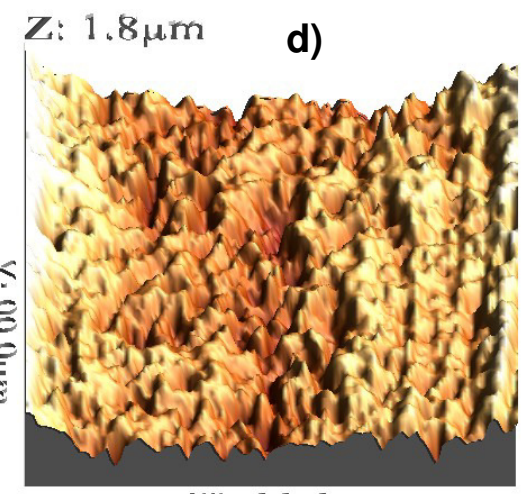

X: 99.9 .2

Figure 8. AFM images from wear tracks a) before treatment and after treatment with at b) $6 \%$ c) $15 \%$ and d) $35 \%$ peroxide solutions.
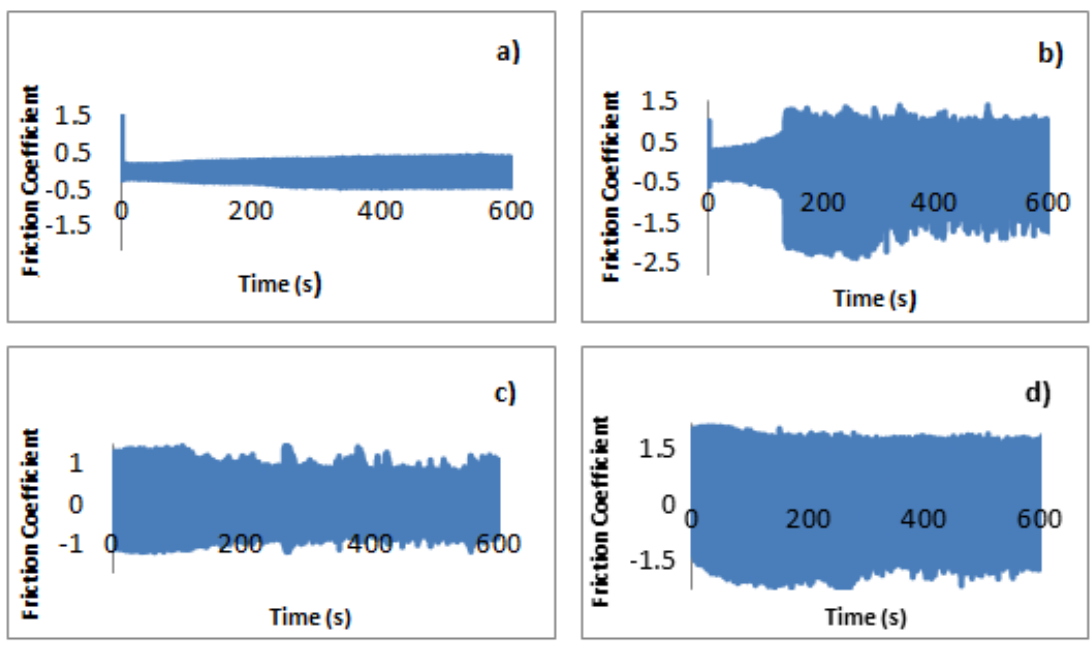

Figure 9. Evolution of the friction coefficient during time for a) untreated samples, and treated samples with different concentrations of peroxide b) $6 \%$, c) $15 \%$ and d) $35 \%$. Negative values are associated with the reversal of the sliding direction.

The results show that the bleaching treatment affects the tribological behaviour of enamel, increasing the friction coefficient and wear loss. The treatment leads to change of the dominant wear mechanism from polishing wear (in untreated samples) to fatigue wear (in treated samples). The reduction of wear resistance after treatment shall be related to structural and morphological changes of the enamel, resulting from demineralization and organic material loss during treatment, as referred above [39]. More research work is needed in order to understand the role of each process (demineralization versus organic loss) and its synergistic effect on the enamel tribological behaviour. 
Overall, although in this in vitro study, the mouth functioning is not fully recreated and the bleaching time exposition was beyond the time usually used in dentistry, the results demonstrate unequivocally that there is a concentration of peroxide that lowers the harmful impact on the enamel properties induced by such treatments. It was found that, for the same level of whitening, $15 \%$ was the concentration that led to the lowest increase of roughness, lowest reduction of hardness and lowest increase of wear. This does not mean that $15 \%$ is the optimum concentration value. Further studies are required to find out that value.

\section{Conclusions}

The present work aimed to study the effect of hydrogen peroxide concentration used in dental bleaching treatments on morphology, hydrophilicity, mechanical and tribological properties of enamel. For this purpose, molar samples were submitted to several bleaching sessions with solutions of peroxide of different concentrations (6,15 and $35 \%)$, until all samples have similar whitening level. The results show that hydrogen peroxide treatment origins:

a) An increase in the enamel surface roughness. The smallest increase in roughness was achieved with $15 \%$ of $\mathrm{H}_{2} \mathrm{O}_{2}$;

b) A decrease of the enamel hardness. The differences between the hardness for the three concentrations are small, but it can be seen that, on average, the samples subjected to treatment with $15 \%$ have the lowest reduction;

c) A negligible change in enamel surface hydrophilicity. The water contact angle almost does not change upon treatment;

d) An increase in the friction and wear coefficients. The peroxide at $35 \%$ led to the largest increase of these parameters. The lowest wear was obtained for $15 \%$.

e) The dominant wear mechanism changes from polishing to delamination.

For the studied concentrations, the bleaching solution at $15 \%$ is the one that produces minor changes in enamel properties after bleaching.

\section{Acknowledgements}

Support of Fundação para a Ciência e Tecnologia (FCT) under the projects UID/QUI/00100/2013 and UID/CTM/04540/2013 is acknowledged. 


\section{References}

[1] Joiner A., 2006. The bleaching of teeth: A review of the literature. Journal of Dentistry, Volume 34, pp. 412-419.

[2] Alqahtani M., 2014. Tooth-bleaching procedures and their controversial effects: A literature review. The Saudi Dental Journal, Volume 26, p. 33-46.

[3] Zhou Z. R., Zheng J., 2008. Tribology of dental materials: a review. Journal of Physics D: Applied Physics, Volume 41, pp. 1-22.

[4] Elfallah H. M., Bertassoni L. E., Charadram N., Rathsam C., Swain M. V., 2015. Effect of tooth bleaching agents on protein content and mechanical properties of dental enamel. Acta Biomaterialia, Volume 20, pp. 120-128.

[5] Giannini M., Soares C. J., Carvalho R. M., 2004. Ultimate tensile strength of tooth structures. Dental Materials, Volume 20, pp. 322-329.

[6] Eimar H., Siciliano R., Abdallah M. N., Nader S. A., Amin W. M., Martinez P. P., Celemin A., Cerruti M., Tamimi F., 2012. Hydrogen peroxide whitens teeth by oxidizing the organic structure. Journal of Dentistry, Volume 40s, pp. e25-e33.

[7] Buchalla W., Attin T., 2007. External bleaching therapy with activation by heat, light or laser A systematic review. Dental Materials, Volume 23, pp. 586-596.

[8] Kwon S. R., Wertz P. W., 2015. Review of the Mechanism of Tooth Whitening. Journal of Esthetic and Restorative Dentistry, June.pp. 1-18.

[9] Young N., Fairley, P. Mohan, V., Jumeaux C., 2012. A study of hydrogen peroxide chemistry and photochemistry in tea stain solution with relevance to clinical tooth whitening. Journal of Dentistry, Volume 40s, pp. e11-e16.

[10] Sulieman M., Addy M., MacDonald E., Rees J. S., 2004. The effect of hydrogen peroxide concentration on the outcome of tooth whitening: an in vitro study. Journal of Dentistry, Volume 32, p. 295-299.

[11] Duschner H., Götz H., White D. J., Kozak K. M., Zoladz J. R., 2006. Effects of hydrogen peroxide bleaching strips on tooth surface colour, surface microhardness, surface and subsurface ultrastructure, and microchemical (Raman Spectroscopic) composition. Journal of Clinical Dentistry, Volume 17, p. 72-78.

[12] Joiner A., Thakker G., Cooper Y., 2004. Evaluation of a $6 \%$ hydrogen peroxide tooth whitening gel on enamel and dentine microhardness in vitro. Journal of Dentistry, Volume 32, p. 27-34.

[13] Joiner A., 2007. Review of the effects of peroxide on enamel and dentine properties. Journal of Dentistry, Volume 35, pp. 889-896.

[14] Miranda C. B., Pagani C., Benetti A. R., Matuda F. S., 2005. Evaluation of the bleached human enamel by scanning electron microscopy. J Appl Oral Sci, 13(2), pp. 204-211.

[15] Sun L., Liang S., Sa Y., Wang Z., Ma X., Jiang T., Wang Y., 2011. Surface alteration of human tooth enamel subjected to acidic and neutral 30\% hydrogen peroxide. Journal of Dentistry, Volume 39, pp. 686-692.

[16] Pinto C. F., Oliveira R., Cavalli V., Giannini M., 2004. Peroxide bleaching agent effects on 
enamel surface microhardness, roughness and morphology. Braz Oral Res, 18(4), pp. 306-311. [17] Costa, S. X. S., Becker A. B., Rastelli A. N. S., Loffredo L. C. M, Andrade M. F., Bagnato V. S.., 2009. Effect of Four Bleaching Regimens on Color Changes and Microhardness of Dental Nanofilled Composite. International Journal of Dentistry, Volume 2009, pp. 1-7.

[18] Meredith L., 2015. The influence of Interproximal reduction on enamel roughness and bacterial adhesion (Thesis, Doctoral of Clinical Dentistry). University of Otago. Retrieved from http://hdl.handle.net/10523/6053

[19] Ivanoff C. S., Horrel T. L., Garcia-Godoy F., Riga A. T., 2011. Dielectrophoresis enhances the whitening effect of carbamide peroxide on enamel. American Journal of Dentistry, 24(5) 259-263.

[20] Sulieman M., Addy M., Macdonald E., Rees J. S., 2004. A safety study in vitro for the effects of an in-office bleaching system on the integrity of enamel and dentine. Journal of Dentistry, Volume 32, p. 581-590.

[21] Martin-Biedma B., Gonzalez-Gonzalez T., Lopes M., Lopes L., Vilar R., Bahillo J., VarelaPatiño P., 2010. Colorimeter and Scanning Electron Microscopy Analysis of Teeth Submitted to Internal Bleaching. Journal of Endodontics, February, 36(2), p. 334-337.

[22] Tiznado-Orozco G. E., Reyes-Gasga J., Elefterie F., Beyens C., Maschke U., Brès E. F., 2015. Wettability modification of human tooth surface by water and UV and electron-beam radiation. Materials Science and Engineering C, Volume 57, pp. 133-146.

[23] Zheng, J., Weng L. Q., Shi M. Y., Zhou J., Hua L. C., Qian L. M., Zhou Z. R.,, 2013. Effect of water content on the nanomechanical properties and microtribological behaviour of human tooth enamel. Wear, Volume 301, pp. 316-323.

[24] Pileicikiene G., Surna A., 2004. The Human Masticatory System From A Biomechanical Perspective: A Review. Stomatologija, Baltic Dental and Maxillofacial Journal, 6(3), pp. 81-84.

[25] Anderson D., 1956. Measurements of stress in mastication. Journal of Dental Research, pp. 175-189.

[26] Barbour M. E., Shellis R. P., An investigation using atomic force microscopy nanoindentation of dental enamel demineralization as a function of undissociated acid concentration and differential buffer capacity. Physics in Medicine and Biology, Volume 52899 910.

[27] Walsh L. J, 2000. Safety issues relating to the use of hydrogen peroxide in dentistry. Australian Dental Journal, Volume 45:(4), 257-269.

[28] Gökay O., Müjdeci A., Algın E., 2004. Peroxide Penetration into the Pulp from Whitening Strips. Journal of Endodontics, December, 30(12), pp. 887-889.

[29] Palo R. M., Valera M. C., Camargo S. E., Camargo C. H., Cardoso P. E., Mancini M. N., Pameijer C. H., 2010. Peroxide penetration from the pulp chamber to the external root surface after internal bleaching. Am J Dent, June, 23(3), pp. 171-174.

[30] Azrak B., Callaway A., Kurth P., Willershausen B., 2010. Influence of Bleaching Agents on Surface Roughness of Sound or Eroded Dental Enamel Specimens. J Esthet Restor Dent, Volume 22, pp. 391-401. 
[31] Barron R. P., Carmichael R. P., Marcon M. A., Sàndor G. K., 2003. Dental Erosion in Gastroesophageal Reflux Disease. J Can Dent Assoc, 69(2), pp. 84-89.

[32] Dawes C., 2003. What Is the Critical pH and Why Does a Tooth Dissolve in Acid?. Journal of the Canadian Dental Association, December, 69(11), p. 722-724.

[33] Davari A. R., Danesh Kazemi A. R., Ataei E., Vatanpour M., Abdollahi H., 2012. Effects of Bleaching and Remineralising Agents on the Surface Hardness of Enamel. J Dent Shiraz Univ Med Scien, 13(4), pp. 156-163.

[34] Wilson T. G., Love B., 1995. Clinical effectiveness of fluoride-releasing elastomers.II. Enamel microhardness levels. American Journal of Orthodontic's and Dentofacial Orthopedics, April, 107(4), pp. 379-381.

[35] Götz H., Duschner H., White D. J., Klukowska M. A., 2007. Effects of elevated hydrogen peroxide 'strip' bleaching on surface and subsurface enamel including subsurface histomorphology, micro-chemical composition and fluorescence changes. Journal of Dentistry, Volume 35, pp. 457-466.

[36] Zantnera C., Beheim-Schwarzbach N., Neumann K., Kielbassa A. M., 2007. Surface microhardness of enamel after different home bleaching procedures. Dental Materials, Volume 23, pp. 243-250.

[37] Araujo F., Baratieri L., Araújo É., 2010. In Situ Study of In-office Bleaching Procedures Using Light Sources on Human Enamel Microhardness. Operative Dentistry, 35(2), pp. 139146.

[38] Potocnik I., Kosec L., Gaspersic D., 2000. Effect of 10\% Carbamicle Peroxide Bleaching Gel on Enamel Microhardness, Microstructure, and Mineral Content. Journal of Endodontics, April, 26(4), pp. 203-206.

[39] Mundra S., Mohan V., Gwyer J., Young N., Franklin S.E., Gerhardt L.-C., 2015. Hardness, friction and wear studies on hydrogen peroxide treated bovine teeth. Tribology International, Volume 89, pp. 109-118.

[40] Figueiredo-Pina C. G., Patas N., Canhoto J., Cláudio R., Olhero S. M., Serro A. P., Ferro A. C., Guedes M., 2016. Tribological behaviour of unveneered and veneered lithium disilicate dental material. Journal of the mechanical behavior of biomedical materials, Volume 53 , pp. 226-238.

[41] Figueiredo-Pina C. G., Monteiro A., Guedes M., A. Maurício, Serro A. P., Ramalho A., Santos C., 2013. Effect of feldspar porcelain coating upon the wear behavior of zirconia dental crowns. Wear, Volume 297, pp. 872-877.

[42] Zheng L., Li Y., Zheng J., Wen M. Zhang Y. F., Qian L.M., Zhou Z.R., 2013. A comparative study on the sliding wear behaviors of human tooth enamel, $\mathrm{Cu}-\mathrm{Zn}$ alloy and Al2O3 ceramic. Wear, Volume 301(1-2), 308-315. 